\title{
Teaching and thinking on Mechanical Engineering English in private undergraduate university
}

\author{
Tingzhou Ning
}

College of Mechanical and Electrical Engineering, Zaozhuang University, Zaozhuang, Shandong, China

email: ning-tingzhou@163.com

\begin{abstract}
Keywords: private undergraduate university; Mechanical Engineering English; final exams;
\end{abstract} reasons; measures

\begin{abstract}
In order to improve the teaching quality of Mechanical Engineering English in private undergraduate university, firstly, two senior undergraduate classes of Mechanical Engineering English final exam scores were analyzed in private undergraduate university Shandong University of $\mathrm{X}$ in 2017-2018 school year, secondly, the reasons were analyzed from various angles, finally, the corresponding measures were put forward. These provide some references for the teaching of mechanical engineering English in private undergraduate university.
\end{abstract}

\section{民办本科高校《机械工程专业英语》教与思 \\ 宁廷州 \\ 本庄学院机电工程学院, 束庄, 山东, 中国 \\ email: ning-tingzhou@163.com}

关键词：民办本科高校；机械工程专业英语；期末考试；原因；措施

中文摘要: 为提高民办本科高校《机械工程专业英语》教学质量, 首先分析了民办本科高校山东 $\mathrm{x}$ 学 院 2017-2018 学年两个大四本科生班级《机械工程专业英语》期末考试成绩, 其次从多个角度分析了 原因, 最后提出了与之相对应的措施, 为民办本科高校《机械工程专业英语》的教学提供了借鉴和参 考。

\section{1. 引言}

《机械工程专业英语》为机械类大四本科生必修课程, 通过《机械工程专业英语》的学 习, 可以提高学生在专业领域阅读原文专业书刊和翻译国外设备技术文献的能力, 同时巩固 和加深已学的专业知识, 了解本学科的发展前沿及国外本学科领域的发展趋势 ${ }^{[1]}$ 。

本文首先分析了民办本科高校山东 $\mathrm{X}$ 学院 2017-2018 学年两个大四本科生班级《机械工 程专业英语》期末考试成绩, 其次从多个角度分析了原因, 最后提出了与之相对应的措施, 为民办本科高校《机械工程专业英语》的教学提供借鉴和参考。 


\section{2. 期末考试成绩分析}

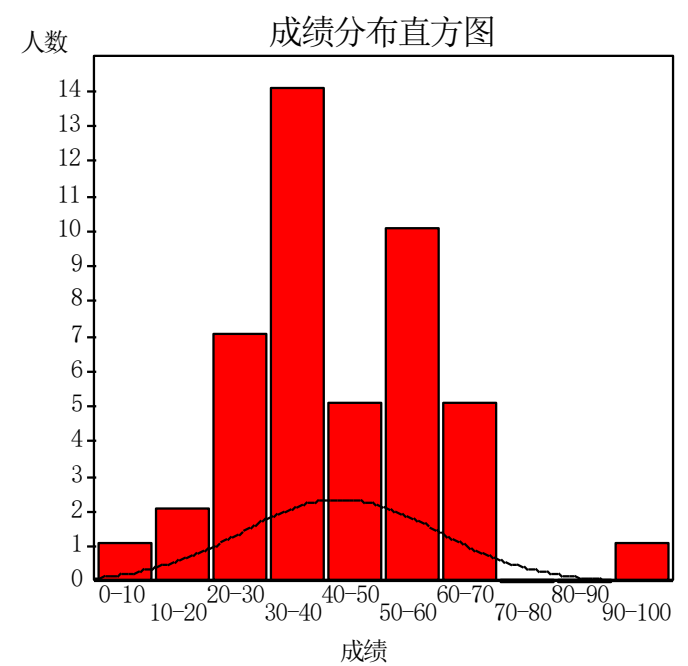

图 11 班期末考试成绩分布直方图

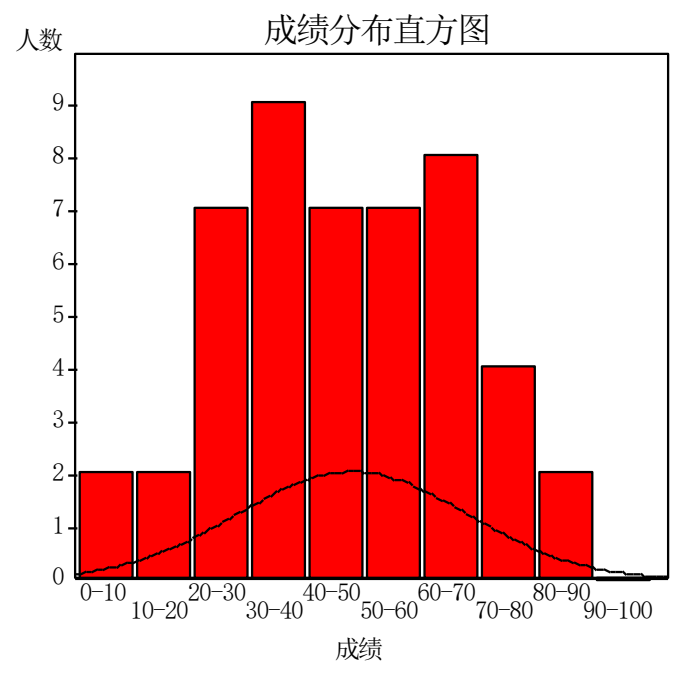

图 22 班期末考试成绩分布直方图

表 11 班期末考试成绩统计分析表

\begin{tabular}{|c|c|c|c|c|c|c|c|}
\hline 平均分 & 42.60 分 & 满分率 & $0.00 \%$ & 标准差 & 16.93 & 及格率 & $13.33 \%$ \\
\hline 最高分 & 92 分 & 优秀率 & $2.22 \%$ & 最低分 & 4 分 & 良好率 & $2.22 \%$ \\
\hline
\end{tabular}

表 22 班期末考试成绩统计分析表

\begin{tabular}{|c|c|c|c|c|c|c|c|}
\hline 平均分 & 46.73 分 & 满分率 & $0.00 \%$ & 标准差 & 19.37 & 及格率 & $29.17 \%$ \\
\hline 最高分 & 83 分 & 优秀率 & $0.00 \%$ & 最低分 & 8 分 & 良好率 & $4.17 \%$ \\
\hline
\end{tabular}

图 1、表 1 展示了 1 班期末考试情况。从图 1 中可以看出, 该班考试成绩在平均分处未 达到极值, 直方图呈非正态分布。从表 1 中可以看出, 考试成绩平均分为 42.6 分, 相对预测 平均分为 75 分, 有些低; 标准差为 16.93 , 表明学生得分差异性较大; 试卷难度系数为 0.43 , 难度得当; 试题区分度为 0.40 , 区分度较好。

图 2、表 2 展示了 2 班期末考试情况。从图 2 中可以看出, 该班考试成绩在 20 分-70 分 之间每隔 10 分的分数段基本均衡, 直方图呈非正态分布。从表 2 中可以看出, 考试成绩平均 分为 46.73 分, 相对预测平均分为 75 分, 有些低; 标准差为 19.37, 表明学生得分差异性较 大; 试卷难度系数为 0.47 , 难度得当; 试题区分度为 0.48 , 区分度较好。

\section{3. 原因分析}

(1) 学校考试制度的不完善

由于大四学生已经多次参加过所在学校的期末考试, 熟悉所在学校的考试情况, 即期末 考试不过, 补考过, 补考不过, 毕业清考过。在这种恶性循环下, 学生对期末考试严重缺乏 认识, 使得学生对期末考试形成一种 ‘不惧怕” 的心理, 久而久之, 期末考试也就失去了其 本身的意义和价值。

\section{(2) 学生英语底子薄弱}

虽然《机械工程专业英语》相比普通英语增加了些专业性, 但在词汇量和语法上有相当 部分的重叠。民办本科高校学生大多是压 “本科线” 进入所在学校的, 文化基础课相对较弱 [2], 英语底子不是很好, 如词汇量不够、语法不够扎实等, 使得学生在学习《专业英语》的 过程中缺乏必要的英语基础知识, 因此学生在学习过程中比较吃力, 期末考试难以取得理想 
的成绩。

（3）学生专业基础知识不扎实

虽然《机械工程专业英语》具有较强的专业性，但其很多知识点都来源于专业基础知识。 如果专业基础知识掌握不扎实, 在听课过程中就很难理解与之相对应的内容 ${ }^{[3]}$ 。而且民办本 科高校的许多学生大都没有形成良好的学习习惯, 在学习专业基础课的时候存在 “课前不预 习、课上不听讲、课下不复习' 的不良学风, 很容易形成 “听不懂” 的局面, 专业基础知识 也就很难掌握牢固。

(4) 教师教学方法过于单一

由于教学过程中采用传统的授课方式, 没有采用多媒体、匹配专业基础知识复习、师生 互动等手段, 使得本身就比较难的英语课程变得更加枯燥无味, 久而久之, 学生便失去了学 习该课程的兴趣 ${ }^{[4-5]}$ 。因此，学生在期末考试中很难取得理想的成绩。

\section{4. 对策分析}

（1） 完善考试制度，杜绝考试作弊

为营造良好的考试环境, 必须建立一套完整的考试制度, 使学生对考试形成一种 “敬畏” 的态度，做到 ‘不敢抄、不想抄、不能抄”。“千里之行，始于足下’，考试制度的执行必须从 低年级开始, 一直到大四本科毕业为止, 持续不解的抓下去, 良好的考试环境也就自然形成。

(2) 提升《大学英语》学习的重要性

无论是《机械工程专业英语》, 还是普通《大学英语》, 在词汇量和语法上有相当部分的 重叠。《大学英语》为大学一二年级必修课程, 而一二年级学生相比来说学习态度较为端正, 此时应该在高中毕业的基础上进一步提升英语的词汇量和语法知识, 这样在大四学习《机械 工程专业英语》时具有扎实生的英语基础知识，学习过程就不会那么困难。

(3) 注重学生专业基础知识的提高

《机械工程专业英语》为一门专业性较强的课程, 涉及到《机械制图》、《机械设计》、《机 械原理》、《先进制造技术》等课程。通常来说, 这些课程均为专业基础课程, 而且在二三年 级均已经学习过。如果学生前期能够较好的掌握这些专业基础知识, 那么在学习《机械工程 专业英语》就很容易形成语言上的互换。因此，应该注重学生专业基础知识的提高。

（4） 教师改变教学方式方法

教师的教学方法对于学生的学习具有重要的影响, 单一的教学方式很难提高学生学习的 兴趣。因此, 《机械工程专业英语》教学过程中, 必须采用灵活机动、多种多样的教学方式和 方法, 如课堂前的 $1 / 4$ 可讲授本节课所涉及到的专业基础知识、英语词汇和语法, 如课堂中可 以对学生进行提问或由学生对部分段落进行翻译, 由此和学生形成良好的互动, 又如可采用 多媒体播放语音或相关视频等提升课堂的趣味性。

\section{5. 结束语}

《机械工程专业英语》为一门语言性和专业性较强的课程, 学校必须完善考试制度, 学 生必须要提高《大学英语》学习的重要性、注重专业基础知识的提高, 教师必须要改变教学 方式方法，由此才能真正提高《机械工程专业英语》教学质量。

\section{References}

[1] GAO Xiao-wang, An Analysis on the Teaching Methods of Mechanical Engineering English of Vocational and Technical Institutions, Journal of Educational Institute of Jilin Province, vol.28, pp. 99-100, 2012. 
[2] YUAN Ying-cai, CHAI Cheng-wen, Major in Mechanical Engineering English Teaching Method Research, Education Teaching Forum, pp. 180-181,2017.

[3] GUAN Xiao-tian, CHANG Men, DUAN Ming-yang, et al, Study on Teaching Reform on Specialized English for Mechanical Engineering Based on Enterprise Requirement, Journal of North China Institute oI Aerospace Engineering, vol.24, pp. 55-57, 2014.

[4] CHEN Sa, MAI Yunfei, LUO Yanjie, Teaching Reform of Mechanical Engineering English, Science and Technology Innovation Herald, pp. 168-169, 2014.

[5] WANG Ju, Exploration on Teaching of Mechanical Engineering Professional English in University, Mechanical Management and Development, vol. 24, pp. 171-172, 2009. 